\title{
BMJ Open Effect of the comprehensive smoke-free law on time trends in smoking behaviour in primary healthcare patients in Spain: a longitudinal observational study
}

To cite: Pons-Vigués M, Rando-Matos $Y$, RodriguezBlanco T, et al. Effect of the comprehensive smoke-free law on time trends in smoking behaviour in primary healthcare patients in Spain: a longitudinal observational study. BMJ Open 2019;9:e020120. doi:10.1136/ bmjopen-2017-020120

- Prepublication history and additional material for this paper are available online. To view please visit the journal online (http://dx.doi.org/10.1136/ bmjopen-2017-020120).

Received 16 0ctober 2017 Revised 18 October 2018 Accepted 11 December 2018

Check for updates

(C) Author(s) (or their employer(s)) 2019. Re-use permitted under CC BY-NC. No commercial re-use. See rights and permissions. Published by BMJ.

For numbered affiliations see end of article.

Correspondence to Dr Mariona Pons-Vigués; mponsv@idiapjgol.info

\section{ABSTRACT}

Objective This study aimed to analyse the impact of comprehensive smoke-free legislation (SFL) on the prevalence and incidence of adult smoking in primary healthcare (PHC) patients from three Spanish regions, overall and stratified by sex.

Design Longitudinal observational study conducted between 2008 and 2013.

Setting 66 PHC teams in Catalonia, Navarre and the Balearic Islands (Spain).

Participants Population over 15 years of age assigned to PHC teams.

Primary and secondary outcomes measures Quarterly age-standardised prevalence of non-smoker, smoker and ex-smoker and incidence of new smoker, new exsmoker and ex-smoker relapse rates were estimated with data retrieved from $\mathrm{PHC}$ electronic health records. Joinpoint analysis was used to analyse the trends of agestandardised prevalence and incidence rates. Trends were expressed as annual percentage change and average annual percent change.

Results The overall standardised smoker prevalence rate showed a significant downward trend (higher in men than women) and the overall standardised ex-smoker prevalence rate showed a significant increased trend (higher in women than men) in the three regions. Standardised smoker and ex-smoker prevalence rates were higher for men than women in all regions. With regard to overall trends of incidence rates, new smokers decreased significantly in Catalonia and Navarre and similarly in men and women, new ex-smokers decreased significantly and more in men in Catalonia and the Balearic Islands, and ex-smoker relapse increased in Catalonia (particularly in women) and decreased in Navarre.

Conclusions Trends in smoking behaviour in PHC patients remain unchanged after the implementation of comprehensive SFL. The impact of the comprehensive SFL might have been lessened by the effect of the preceding partial SFL.

\section{INTRODUCTION}

Smoking is the leading worldwide cause of preventable death. ${ }^{1}$ According to WHO, it
Strengths and limitations of this study

- To our knowledge, no studies have been published on the impact of the Spanish comprehensive smoke-free legislation in all adult primary healthcare patients.

- Used as a research tool, electronic health records portray real life conditions and provide comprehensive, long-term health histories from a large population sample.

- The results of quarterly data by Joinpoint analysis provides more precise information than an analysis before-after the implementation of the law.

- This study only considered age and sex since other variables were not available for the adjusted analysis.

- The study period started later (shorter follow-up) in the Balearic Islands to ensure reliability of data.

is estimated that at least 30 million people may die prematurely from tobacco-related diseases. ${ }^{2}$ Legislative measures have been adopted to protect people's health in public areas and workplaces. These include increasing the price of cigarettes, banning advertising, sponsorship and smoking in workplaces and public spaces, displaying warnings on tobacco packets and implementing prevention programmes. ${ }^{3}$

Some studies show a decrease in smoking prevalence since the introduction of smokefree legislation (SFL). ${ }^{4-9} \mathrm{~A}$ meta-analysis of 26 studies on the effect of the smoke-free workplace in various countries concluded in 2002 that smoke-free workplaces protect non-smokers from the dangers of passive smoking, and they encourage smokers to reduce tobacco consumption. The authors concluded that SFL is associated with a 
$3 \%-4 \%$ reduction in tobacco consumption. ${ }^{10}$ In contrast, a Cochrane review published in 2016, which included 24 studies on smoking behaviour, showed inconsistencies regarding the impact of smoking bans on smoking prevalence and tobacco consumption. ${ }^{11}$

On 1 January 2006, the Spanish government introduced a partial SFL (Law 28/2005), ${ }^{12}$ which included regulations on the sale, supply, consumption and advertising of tobacco products. Smoking was banned at all indoor public and private workplaces with the exception of the hospitality sector, where partial restrictions were established depending on the size of the establishment, that is, in bars or restaurants smaller than $100 \mathrm{~m}^{2}$ the managers could decide whether to allow smoking in the premises (Law 28/2005). The mean concentration of nicotine subsequently decreased by $60 \%$ in public administration offices and by $97.4 \%$ in private workplaces, but in areas where smoking was permitted, including bars and nightclubs, no changes were found. ${ }^{13-15}$ This prompted the enactment of comprehensive SFL (Law 42/2010), ${ }^{16}$ which came into force in January 2011. This comprehensive law expanded smoking restriction to all hospitality venues of any size and, as a result, smoking was forbidden in all enclosed public places, including bars, restaurants and nightclubs, and in some open-air public places such as playgrounds.

Some studies have analysed the impact of these two Spanish laws on smoking prevalence. However, most have been based on health surveys ${ }^{13}{ }^{17-20}$ and surveys of hospitality workers. ${ }^{21} 22$ Moreover, some studies evaluate only the partial law, ${ }^{13} 1718$ whereas others analyse the compound impact of both laws. ${ }^{19} 202324$ The results of these studies are often conflicting; while some conclude that the partial SFL does not have any effect on the downward trend in the prevalence of smokers, ${ }^{13} 1923$ other studies show a reduction in smoking prevalence, ${ }^{24}$ an increase of the smoking quit ratio in the short term ${ }^{18}$ and minor increases in the prevalence of active smoking. ${ }^{20}$

Only one study conducted in PHC patients evaluates the impact of the Spanish partial SFL, including smoking prevalence in active smoker workers that attended PHC visits; 1 month after the implementation of the law, a $9.5 \%$ decline of smokers was observed. ${ }^{25}$ To our knowledge, no studies have been published on the impact of the Spanish comprehensive SFL in all adult PHC patients. In view of the pivotal role of PHC services in smoking habits, we consider that the information registered in PHC records is a good proxy to generate up-to-date evidence and to evaluate the impact of comprehensive SFL in the general population.

We hypothesised that Law 42/2010 does reduce exposure to environmental cigarette smoke and its harmful effects and crucially, it promotes smoking denormalisation in society, thus encouraging smokers to quit or reduce consumption and discouraging non-smokers from initiating this habit. Accordingly, the aim of this study was to examine the impact of the Spanish comprehensive SFL (Law 42/2010) on the prevalence and incidence of adult smoking in PHC patients in three regions (Catalonia, Navarre and Balearic Islands), during the 2008-2013 period, overall and stratified by sex.

\section{METHODS}

Design, study participants and information source

Longitudinal observational study of the adult population assigned to 66 PHC teams (PHCTs) in three Spanish regions: Catalonia, Navarre and the Balearic Islands (22 PHCTs per region). Inclusion criteria of the PHCTs were: (1) Computerisation of electronic health records (EHRs) by 1 January 2005 in Catalonia and Navarre, and 2008 in the Balearic Islands. (2) Agreement to participate in the study by over $80 \%$ healthcare professionals working in each PHCT. Random cluster sampling was stratified by region, with PHCT as randomisation unit. ${ }^{26}$ In each PHCT, general practitioners (GPs) with a patient list between 400 and 3000 were selected. GPs with shorter patient lists were accepted if it was their first year in the PHCT.

The study period included from the first quarter of 2008 to the fourth quarter of 2013 in Catalonia and Navarre; and from the second quarter of 2010 to the fourth quarter of 2013 in the Balearic Islands. The study started in 2008 to obtain data from the 2 years prior analysis, a requirement to adequately construct the variable ex-smoker. In the case of the Balearic Islands, the study started later to ensure reliability of data.

Inclusion criteria for patients were: (1) Population allocated to the selected PHCT for the whole 2007-2013 period in Catalonia and Navarre; in the Balearic Islands, patients allocated to the selected PHCT in 2013 and evaluated retrospectively (no historical annual comprehensive register of allocation of patients was available). (2) Age $\geq 16$ years and $\leq 100$ years in 2007 in Catalonia and Navarre, and 2010 in the Balearic Islands. (3) In order to have data in the EHR collected during the study period, a minimum of one visit to their PHCT during the 20072013 period in Catalonia and Navarre and 2010-2013 in the Balearic Islands. (4) Information on smoking habit recorded in the EHR for the quarter prior to the onset of the study: last quarter of 2007 in Catalonia and Navarre and first quarter of 2010 in the Balearic Islands, to enable the adequate construction of the various variables. Since smoking is not an acute condition, this information was considered valid until new information was entered. Thus, closed cohorts (with fixed membership, where nobody is added nor excluded after the study begins) were constituted in the three regions. Figure 1 shows the flow chart of the study.

Data were retrieved from the Registry of Preventive Services in Primary Care (REGIPREV) database,${ }^{26}$ which contains encrypted and anonymised clinical information recorded in the EHR by these 66 PHCTs. An algorithm was applied to extract equivalent data from the health records software used in each region: 'ECAP' in Catalonia, 'Atenea' in Navarre and 'e-siap' in the Balearic Islands. 
Initial Database - Patients assigned to the PHC teams for a minimum of 1 year:

Catalonia: 548,695 patients (2007-2013)

Navarre: 295,172 patients (2007-2013)

Balearic Islands: 354,583 patients (Assigned in 2013)

Patients assigned to professional with reduced patient-list ${ }^{\mathrm{a}}$ :

Catalonia: 27 patients

Navarre: 0 patients

Balearic Islands: 17 patients

Patients with no PHC visit during

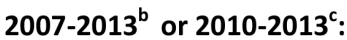

Catalonia: 44,676 patients

Navarre: 22,685 patients

Balearic Islands: 39,943 patients

Patients without data on smoking status at the onset:

Catalonia: 210,610 patients

Navarre: 156,509 patients

Balearic Islands: 124,030 patients

\title{
Patients active throughout the study period with \\ smoking habit recorded in the last quarter of $2007^{b}$ \\ or the first quarter of $2010^{c}$ : \\ Catalonia: 141,071 patients \\ Navarre: 73,644 patients \\ Balearic Islands: 178,251 patients
}

\author{
Patients belonged to 22 Primary Health Care Teams in each region \\ a atypical patient-list $<400 \mathrm{o}>3000$; GP with shorter patient lists were accepted if it was their first \\ year in the Primary healthcare team \\ ${ }^{\mathrm{b}}$ In Catalonia or Navarre \\ ${ }^{c}$ In the Balearic Islands \\ PHC: Primary healthcare
}

Figure 1 Flow chart of patients included in the study, by region.

Codes of the International Classification of Diseases, ninth revision in the Balearic Islands (ICD-9) and tenth in Catalonia (ICD tenth revision) ${ }^{27}$ and the International Classification of Primary Care, second edition, in Navarre (ICPC-2) ${ }^{28}$ were used.

\section{Variables}

Information on smoking is registered in the EHRs using diagnostic codes to classify diseases (codes F17.0 to F17.9 and Z72.0 of the ICD-10, 305.1 of the ICD-9 and P17 of the ICPC-2), and also clinical variables (number of cigarettes per day, history of smoking, history of advice for smoking cessation). This information is stored with the entry date (online supplementary file table S1). With the information on smoking status and entry date we created the following dependent variables at the end of each quarter of the study period:

Smoking status (three categories): (1) Non-smoker: patient that has never been a tobacco consumer. (2) Smoker: tobacco consumer or patient that has quit smoking for less than 12 months. (3) Ex-smoker: patient who used to smoke but has quit smoking for at least 12 continuous months. When the EHR did not 
contain a new entry related to smoking status (diagnostic codes or clinical variables), we considered that no changes in smoking status had taken place and thus the last observation was still valid.

New smoker: patient non-smoker for the 12 months prior to the considered quarter that has started smoking during the said quarter.

New ex-smoker: the patient was a smoker 2 years before the considered quarter and has continuously abstained from tobacco for at least 12 months.

Ex-smoker relapse: patient ex-smoker during the 12 months prior to the considered quarter that has started smoking again during the said quarter.

For higher accuracy in prevalence and incidence changes, quarterly estimates were calculated.

The following variables of each patient were collected at baseline (2008 in Catalonia and Navarre; 2010 in the Balearic Islands): age, sex (male/female), annual number of health problems and annual number of PHC visits. The number of health problems was used as a morbidity indicator; it was calculated as the sum of the number of different active health problems (chronic and acute, coded by ICPC-2).

\section{Data analyses}

Descriptive statistics were used to summarise overall information. Categorical variables were expressed as percentage, and continuous variables as mean (SD) or median (IQR).

Because the three regions used different EHR systems (different standards and computer programs), have different socioeconomic characteristics, different complementary measures to the SFL and also due to the shorter study period in the Balearic Islands, we performed a stratified analysis per region, overall and by sex. Age-standardised prevalence (non-smokers, smokers and ex-smokers) and incidence (new smokers, new ex-smokers and ex-smoker relapse) rates were calculated for each quarter using the direct method, and based on the European standard population (rates per 10000 inhabitants).

Joinpoint analysis was used to analyse the trends of age-standardised prevalence (smokers and ex-smokers) and incidence rates (new smokers, new ex-smokers and ex-smoker relapse) and to identify the best-fitting points (the 'joinpoints', in calendar quarters) where the rate changes significantly in the linear slope of the temporal trend. Significant changes include changes in direction or in the rate of increase or decrease..$^{29}$ Joinpoint analysis estimates the magnitude of the increase or the decrease observed in each specified time interval by estimating the annual percentage change (APC). In addition, temporal trends were expressed as the average annual percent change (AAPC), computed to summarise and compare these trends over the entire time period. Because the outcomes originate from repeated measurements, control for the autocorrelation errors was used; 95\% CIs of APC and AAPC were calculated. The trend of non-smoker prevalence rates was not calculated because the study consisted of a closed cohort where no new participants are recruited, and thus the prevalence of non-smokers can either remain the same or decrease, but never increase.

Analyses were performed using Stata/SE V.14.2 for Windows (Stata Corp, College Station, Texas, USA). The Joinpoint regression analysis was carried out using the Joinpoint software from the Surveillance Research Programme of the US National Cancer Institute (ref. Joinpoint Regression Program, V.4.6.0. April, 2018; Statistical Research and Applications Branch, National Cancer Institute) (https://surveillance.cancer.gov/branches/ $\operatorname{srab} /)$.

\section{Patient and public involvement}

Study participants were not involved in the development of the research question or the outcome measures, nor in the design of the study. The results will be presented to citizens through informative activities and the media.

\section{RESULTS}

The study population was 392966 patients: 141071 in Catalonia, 73644 in Navarre and 178251 in the Balearic Islands (figure 1). At the onset of the study, the mean age was 50.4 years in Catalonia, 54.0 years in Navarre and 47.7 years in the Balearic Islands. In the three cohorts more than half were women $(>51 \%)$. Catalonia presented the highest median number of visits (9, IQR: 3-16) and the Balearic Islands presented the highest number of recorded active health problems per patient (median 10, IQR: 6-16) (table 1).

The overall standardised smoker prevalence rates per 10000 inhabitants were of similar magnitude in the three regions (ranges of 3579.2-4138.9 in Catalonia, 3719.8-4034.2 in Navarre and 3787.4-4029.7 in the Balearic Islands). The prevalence rate decreased in Navarre during the whole study period, decreased in the Balearic Islands in most quarters and also in Catalonia except for the last year. These rates were higher for men than for women in all regions (online supplementary file table S2-S7). A significant downward overall trend of smoker prevalence rates was found in Catalonia ( $\mathrm{AAPC}=-2.18)$, Navarre $(\mathrm{AAPC}=-1.44)$ and the Balearic Islands $(\mathrm{AAPC}=-1.75)$; this downward trend was higher for men than for women in the three regions. In Catalonia, the most significant reduction occurred during the period 2010.3-2011.4 $(\mathrm{APC}=-6.75)$, similarly to the Balearic Islands (2010.22012.4; $\mathrm{APC}=-2.19)$, whereas in Navarre it occurred between 2008.1 and 2013.4 ( $\mathrm{APC}=-1.44)$ (tables 2, 3 and 4 , online supplementary file figure $\mathrm{S} 1$ ).

For the whole period, the overall standardised ex-smoker prevalence rates per 10000 inhabitants increased in Navarre, in the Balearic Islands and in Catalonia except for the last year. The rates in Catalonia were higher (ranges of: 1168.5-1781.2 in Catalonia; 313.3-764.1 in Navarre; and 559.3-914.1 in the Balearic Islands). The standardised 
Table 1 Characteristics of the cohort study population by region at the onset of the study (2008 in Catalonia and Navarre, 2010 in the Balearic Islands)

\begin{tabular}{llll}
\hline & $\begin{array}{l}\text { Catalonia } \\
\mathbf{n = 1 4 1 0 7 1}\end{array}$ & $\begin{array}{l}\text { Navarre } \\
\mathbf{n = 7 3 6 4 4}\end{array}$ & $\begin{array}{l}\text { Balearic Islands } \\
\mathbf{n = 1 7 8 2 5 1}\end{array}$ \\
\hline Age (years), SD & $50.37(17.23)$ & $54.04(18.26)$ & $47.65(17.56)$ \\
Sex (female), number (\%) & $72340(51.28)$ & $37898(51.46)$ & $94164(52.83)$ \\
Number of visits, mean (SD); median (IQR) & $11.69(12.19) ;$ & $8.93(9.30) ;$ & $11.01(13.25) ;$ \\
& $9.00(3.00-16.00)$ & $7.00(3.00-12.00)$ & $7.00(3.00-15.00)$ \\
Number of health problems, mean (SD); median (IQR) & $6.23(4.58) ;$ & $9.95(5.39) ;$ & $11.85(7.74) ;$ \\
& $5.00(3.00-8.00)$ & $9.00(6.00-13.00)$ & $10.00(6.00-16.00)$ \\
\hline
\end{tabular}

Patients belonged to 22 primary healthcare teams in each region.

Abbreviations: SD, standard deviation; IQR, interquartile range.

ex-smoker prevalence rates were higher for men than for women in all regions (online supplementary file table S2S7). The overall trend of ex-smoker prevalence rates increased significantly in the three regions throughout the study period but was higher in Navarre (Navarre AAPC $=16.67$; Catalonia AAPC=7.19; Balearic Islands AAPC=14.96). The increase in the prevalence rate of ex-smokers was higher for the 2008.1-2008.2 period in Catalonia, 2008.1-2008.4 in Navarre and for 2010.2-2012.2 in the Balearic Islands, and higher in women in the three regions (women: Catalonia AAPC $=10.87$; Navarre AAPC $=17.30$ and Balearic Islands $\mathrm{AAPC}=19.51$ ) (tables 2, 3 and 4, online supplementary file figure $\mathrm{S} 1$ ).

The overall new smoker standardised incidence rates per 10000 inhabitants showed low values in the three regions (ranges of 7.9-26.8 in Catalonia; 9.5-30.9 in Navarre; $1.6-17.5$ in the Balearic Islands) and higher for men than for women in Catalonia and Navarre (online supplementary file table S2-S7). The overall trend of new smoker incidence rates decreased significantly in Catalonia $(\mathrm{AAPC}=-10.39)$ and Navarre (AAPC $=-9.49)$; additionally, the decline was similar for men and women. In contrast, the overall trend remained stable in the Balearic Islands despite a decrease until 2012.4 ( $\mathrm{APC}=-46.20)$ and a considerable increase from 2012.4 to 2013.4 (APC=1054.2) (tables 2, 3 and 4, online supplementary file figure S2).

The overall standardised new ex-smoker incidence rates per 10000 inhabitants showed higher values in Catalonia (range: 110.7-317.6) than in Navarre (range: 48.6-181.0) and the Balearic Islands (range: 93.7-188.1) (online supplementary file table S2-S7). The overall trend of new ex-smoker incidence rates showed a significant decrease in Catalonia (AAPC $=-7.27$ ) and especially in the Balearic Islands (AAPC $=-11.24)$. This downward trend was higher for men than for women in Catalonia and the Balearic Islands (tables 2, 3 and 4, online supplementary file figure S2).

The overall standardised ex-smoker relapse incidence rates per 10000 inhabitants presented higher values in the Balearic Islands (range: 103.9-576.6) than in Catalonia (range: 70.7-334.5) and Navarre (range: 58.6-230.3) (online supplementary file table S2-S7). The overall trend of ex-smoker relapse incidence rates showed significant increases in Catalonia ( $\mathrm{AAPC}=18.60)$, particularly in women (AAPC=14.56), although a decrease from 2008.1 to 2012.3 was observed $(\mathrm{APC}=-8.40)$. In contrast, Navarre showed significant decreases $(\mathrm{AAPC}=-11.42)$ (tables 2, 3 and 4 , online supplementary file figure S2).

\section{DISCUSSION}

The previous implementation of the partial Spanish SFL could account for the low effectiveness of the comprehensive SFL observed in this study. A significant downward trend of smoker prevalence rates, higher in men than in women, was found in the three regions throughout the study period. Correspondingly, the trend of ex-smoker prevalence rates increased in the three regions, particularly in Navarre and during the period 2008.1-2008.2 in Catalonia, 2008.1-2008.4 in Navarre, and 2010.22012.2 in the Balearic Islands. Even though the standardised ex-smoker prevalence rate was higher for men, the increase in the trend of ex-smoker prevalence rate was higher in women in the three regions. The overall trends of new smoker incidence rates decreased significantly in Catalonia and Navarre and were similar for men and women. Also, the overall trends of new ex-smokers decreased significantly in Catalonia and the Balearic Islands, particularly for men. In addition, the overall trends of ex-smoker relapse increased in Catalonia and decreased in Navarre, more for women than for men in both cases.

The trends of smoker prevalence declined throughout the study and no changes were observed after the implementation of the comprehensive SFL. Indeed, the most significant decrease begins in 2010 in Catalonia (third quarter) and the Balearic Islands and in 2008 in Navarre, prior to the implementation of the comprehensive SFL (1 January 2011). However, the trend in Catalonia shows a drop in the prevalence rate of smokers around the time of the implementation of the law. In contrast, trends in Navarre and the Balearic Islands show a more progressive decline. Comparisons are difficult due to the lack of studies on smoking prevalence and incidence from a PHC perspective and because some studies evaluate the impact of SFL on smoking prevalence with surveys that 


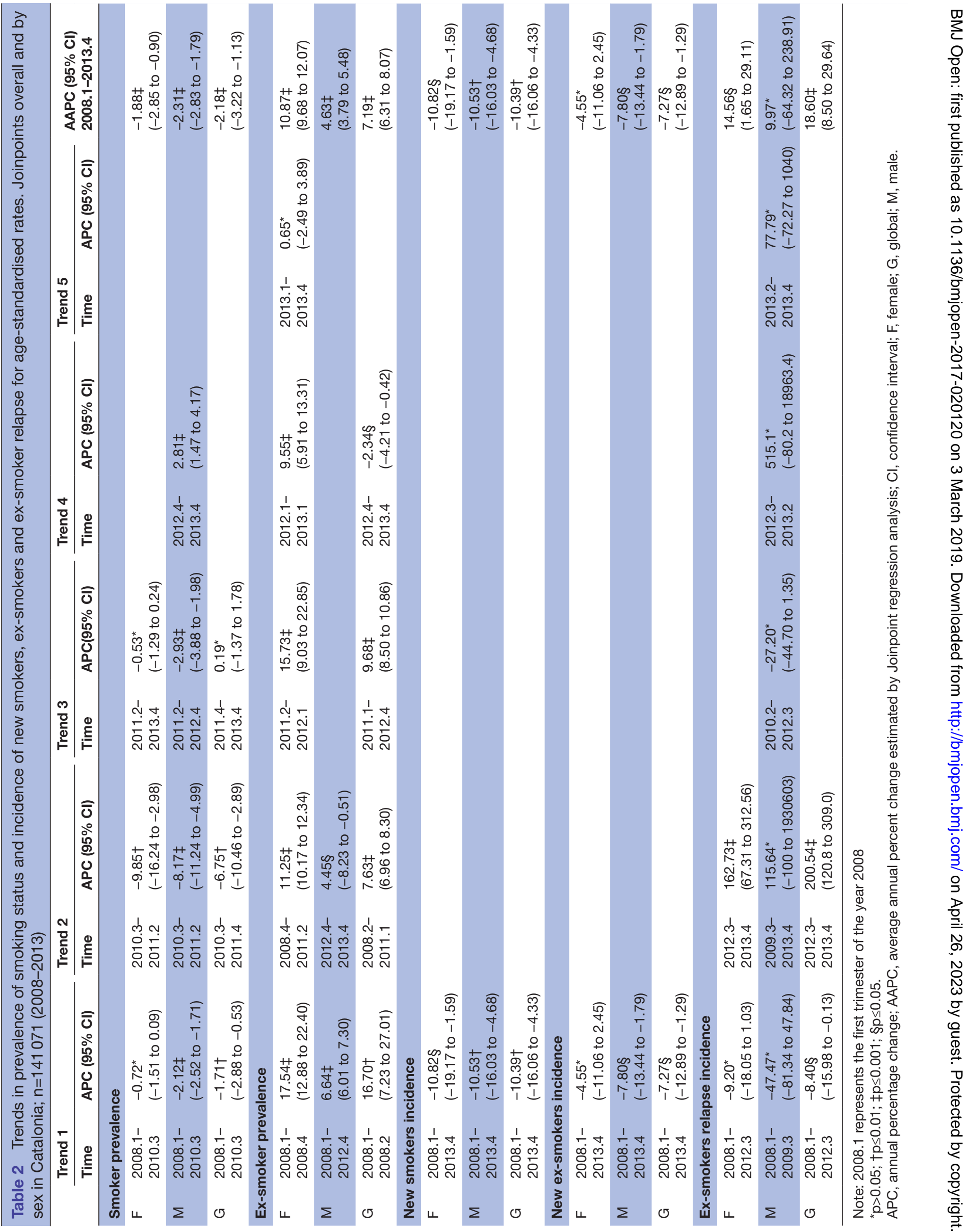




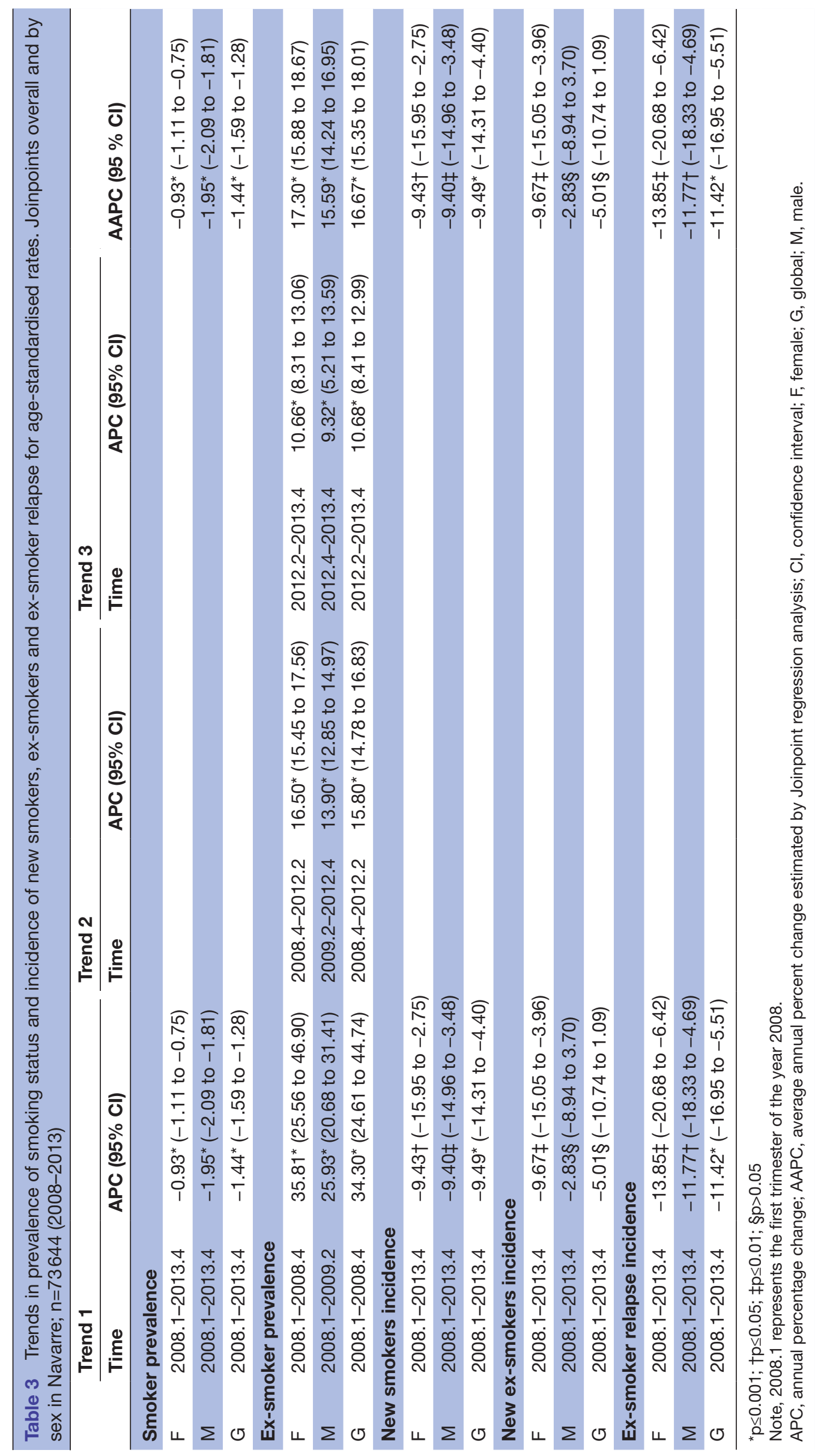




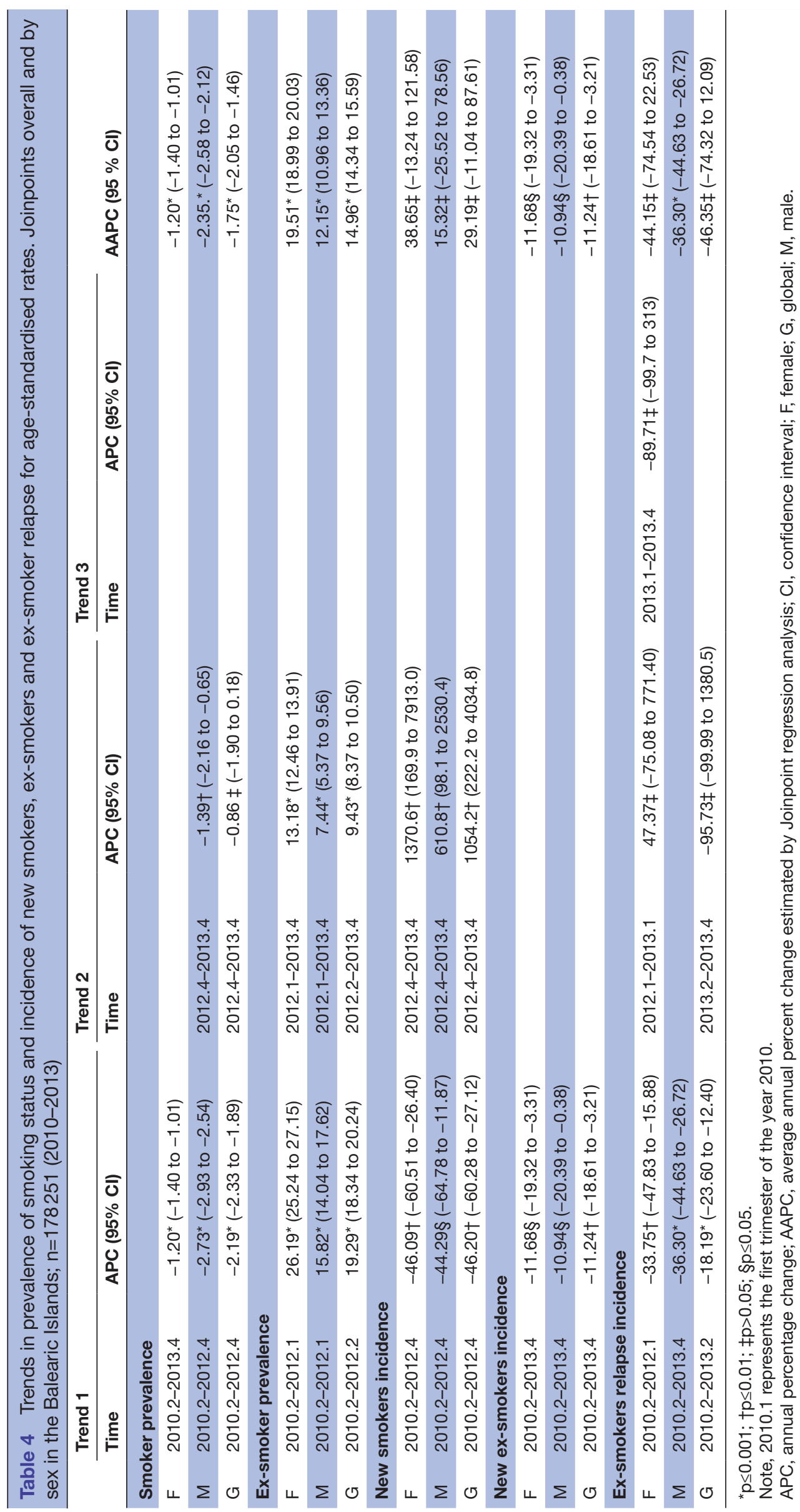


use different methodologies. Two studies that analysed data from surveys of the general population ${ }^{19}{ }^{20}$ did not find a significant decrease in the prevalence of smokers after the Spanish comprehensive law. In contrast, Lidón et $a l^{24}$ showed that after the implementation of both Spanish SFLs, a significant decrease was observed in the smoking prevalence (from $34.5 \%$ to $26.1 \%$, prevalence ratio $=0.76, \mathrm{p}<0.001$ ) of people 16 years of age and older living in Barcelona surveyed in 2004-2005 and followed up in 2013-2014. In addition, National Health Survey data from the 1987-2005 period revealed an annual average absolute decline of $1.0 \%$ in the prevalence of male smokers, whereas women showed an annual average absolute increase in prevalence of $0.2 \%$. Between 2006 and 2014, the prevalence of smokers declined annually by $0.7 \%$ in men and $0.5 \%$ in women. ${ }^{23}$ Although the values of the current study are higher, the steeper decline in the prevalence of smokers in men agree with these data. ${ }^{23}$ Also, one study that estimated the effect of the Spanish SFL for the 2012-2025 period predicted a decrease in smoking prevalence in all age groups and for both sexes, except for women aged 40-64 years. ${ }^{30}$

Concomitantly with the decline in the prevalence trends in smokers, a constant increase of prevalence trends in ex-smokers was observed in the three regions. Other studies failed to note a significant change in the prevalence of ex-smokers after the comprehensive SFL: a difference of only $0.3 \%$ between 2007 and $2011,{ }^{20}$ and a non-significant increase of $3.3 \%$ between 2006 and $2011 .{ }^{19}$ In agreement with a recent evidence review, ${ }^{23}$ we observed a higher increase in the trend of ex-smokers prevalence in women. This review showed that the rate of smoking cessation in men increased $0.9 \%$ annually during the 1987-2014 period, and $1.5 \%$ in women after the partial SFL came into force. The later incorporation of women to smoking might explain these gender differences. We should underscore that other studies that use health surveys as an information source have a higher prevalence of ex-smokers than the prevalence we obtained in this study, especially for Navarre and the Balearic Islands. ${ }^{31}$ This discrepancy could be explained by the misclassification of long-term ex-smokers as non-smokers during the process of computerisation of medical records in the cases where the smoking habit was not sufficiently investigated. ${ }^{32}$

We observed a gradual decline in the new smoker incidence trends in Catalonia and Navarre throughout the study period, whereas incidence trends remained stable in the Balearic Islands (possibly due to the shorter study period or lower rates). A review by Wilson $e t a \vec{l}^{33}$ of two studies that evaluated smoking initiation reported mixed results, while Guerrero $e t a l^{34}$ concluded that the Spanish partial SFL had no effect on new smokers in 2009. In contrast, Pinilla and Abásolo ${ }^{35}$ observed a $6 \%$ decrease in the rate of smoking initiation among young people after the implementation of the same law, with a more positive impact in higher socioeconomic strata. We have not found studies that evaluate the impact of the comprehensive
SFL on the incidence of new smokers. However, our data show a continuation in the trend observed in Pinilla's study $^{35}$ on the impact of the partial law.

The incidence trend in new ex-smokers declined gradually throughout the study period in Catalonia and the Balearic Islands. While the literature to date lacks data on the effect of the SFL on the incidence of new ex-smokers, it provides some information on prevalence. In this respect, one study on the Spanish partial SFL observed an increase of $8 \%$ between 2006 and 2011 in the rate of cessation among adult smokers (age 21 years and older) according to data from the National Health Survey. ${ }^{35}$ In Luxembourg, smoking cessation attributed to the SFL was higher among daily smokers with a higher socioeconomic status. ${ }^{8}$ In our cohort, we observed apparent random increases and declines in the adjusted rates in the three regions throughout the study.

The incidence trend in ex-smoker relapses increased in Catalonia and declined in Navarre constantly throughout the whole period, particularly for women, but the overall trend remained stable in the Balearic islands (most likely because of the shorter study period). However, the literature presents conflicting results regarding smoking relapse. One study on the partial Spanish SFL observed that most people who had succeeded in giving up smoking in 2006 had not relapsed by 2009. ${ }^{34}$ On the other hand, a quasi-experimental study conducted in USA observed that relapse was similar between employees in workplaces with SFL and employees where smoking was permitted. ${ }^{36}$ In contrast, Shang found that comprehensive SFL in bars significantly deters smoking relapse among people aged 21 years and older. ${ }^{37}$ According to Buczkowski et al, ${ }^{38}$ the main reasons for relapse are stress, missing the pleasure obtained from smoking and the smoking environment. Other factors not analysed in our study that might influence relapse rates could explain the variations between regions, for instance living with other smokers, being enrolled in work or clinics cessation programmes, ${ }^{39}$ or the region-specific complementary measures to the SFL (for instance, Foral Law 6/2003, ${ }^{40}$ of smoking prevention, protection from secondhand tobacco smoke and promotion of health with regard to smoking in Navarre). In addition, we should consider the impact of the financial crisis during the study period and the subsequent increase of anxiety and depression in the population. ${ }^{41} \mathrm{In}$ this respect, Navarre was the region with the lowest unemployment rate in Spain according to the 2010 Economically Active Population Survey (unemployment of 11.6\% in Navarre, versus $18.0 \%$ in Catalonia and $22.2 \%$ in the Balearic Islands). According to the 2009 European Health Survey in Spain, these unemployment figures correlate with the prevalence of chronic depression, which was of $3.4 \%$ in Navarre versus $5.4 \%$ in Catalonia and $7.0 \%$ in the Balearic Islands.

The SFL is a keystone of the WHO Framework Convention on Tobacco Control and the MPOWER policy package (M=Monitor; $\mathrm{P}=$ Protect; $\mathrm{O}=\mathrm{Offer} ; \mathrm{W}=\mathrm{Warm}$; $\mathrm{E}=$ Enforce; R=Raise) ${ }^{42}$ The enforcement of Laws 28/2005 
and 42/2010 have significantly advanced smoking control in Spain, in particular the 'Protect people from tobacco' strategy. However, the remaining MPOWER strategies have been patchily implemented and require further development. ${ }^{23}$ On balance, a combination of specific, feasible, pragmatic, sufficiently funded policies and interventions aimed at populations and individuals is essential to achieve progress regarding smoking behaviour.

\section{Limitations and strengths of the study}

It is important to take into account that other than the law, the pattern of tobacco consumption is influenced by factors such as health interventions, level of education, age, civil status, having children and being unemployed. ${ }^{43}$ However, this study only considered age, sex, number of health problems and number of PHC visits since other variables were not available. In addition, many patients were excluded from the study because of lack of baseline data on smoking (missing data are a common problem in studies based on EHR). In order to prevent bias caused by improved smoking records, we excluded the cases with no information at the beginning of the study. The selection criteria and the longitudinal design aimed to maximise the internal validity of the study. Moreover, young people might be under-represented due to their lower use of PHC services. On the other hand, $70 \%$ of the population attends PHC services at least once a year and smokers attend more frequently than no smokers. ${ }^{44}$ In view of the limited length of the study period, particularly in the Balearic Islands, we consider these results a first approximation to be succeeded by follow-up research. We should underscore that rather than just comparing two different periods, Joinpoint analysis evaluates longitudinal trends, thus producing a more accurate assessment. The following characteristics of the study were taken into consideration: scarcity of data prior to the implementation of the SFL; delayed changes in smoking status; possibility of detecting more than one change in smoking trends; and influence of unanticipated factors. While other statistical models could have been used, we believe that Joinpoint is a suitable method to achieve the study objectives, as shown in previous studies. ${ }^{45-47}$

This study provides useful data on the impact of the Spanish comprehensive SFL on adult smoking behaviour in PHC patients. It is crucial to analyse the consequences of a public health law on PHC users. PHC has a pivotal role in smoking cessation because it is the gatekeeper of the health services; it is accessible and provides continuity of care to smokers. ${ }^{48}$ We should also highlight that this study includes the evaluation of novel variables such as incidence of new smokers, new ex-smokers and ex-smoker relapse, which we consider of great relevance in relation to PHC interventions for smoking cessation. Used as a research tool, EHRs portray real life conditions and provide comprehensive, long-term health histories from a large population sample, ensure high representativeness and external validity, and minimise potential recall bias. The results are only generalisable to PHC users. To our knowledge, this study is among the first to show quarterly data from EHRs.

\section{CONCLUSIONS}

The introduction of the Spanish comprehensive SFL (Law 42/2010) does not significantly modify incidence and prevalence trends of smoking behaviour in PHC adult patients in Catalonia, Navarre and the Balearic Islands. The impact of the comprehensive SFL might have been lessened by the effect of the previous implementation of the partial SFL (Law 28/2005). The current article provides baseline data for future research into the effectiveness of this law. In addition to specific factors associated with smoking behaviour (such as the price of a pack of cigarettes or funding of smoking cessation services), future studies should consider socioeconomic status and age groups.

\section{Author affiliations}

${ }^{1}$ Fundació Institut Universitari per a la recerca a l'Atenció Primària de Salut Jordi Gol i Gurina (IDIAPJGol), Barcelona, Spain

${ }^{2}$ Universitat Autònoma de Barcelona, Bellaterra (Cerdanyola del Vallès), Spain ${ }^{3}$ Departament d'Infermeria, Universitat de Girona, Girona, Spain

${ }^{4}$ Centre d'Atenció Primària (CAP) Florida Nord, Institut Català de la Salut (ICS), Hospitalet de Llobregat, Barcelona, Spain

${ }^{5}$ Primary Care Research Unit of Mallorca, Baleares Health services-lbSalut, Palma, Spain

${ }^{6}$ Balearic Islands Health Research Institute (IdISBa), Palma, Spain

${ }^{7}$ Equipo de Atención Primaria de Tafalla, Servicio Navarro de Salud, Barasoain, Spain

Acknowledgements The authors thank all professionals of the 66 PHC teams who volunteered to participate in the study. The authors also thank Josep M ElorzaRicart, Magdalena Rosell-Murphy, Lluís Martínez, Javier Baquedano, Javier Arranz, $\mathrm{M}^{\mathrm{a}}$ Ángeles Nuin and Carlos Martín-Cantera for their collaboration, and Eulàlia Farré for the English translation. This article forms part of the doctoral dissertation of Yolanda Rando-Matos at the Universitat Autònoma de Barcelona (Department of Medicine of the Autonomous University of Barcelona).

Contributors BB, TR-B, MP-V, JLIB-M and CV-F designed the study and wrote the protocol. YR-M, MP-V and JLIB-M conducted literature searches and provided summaries of previous research studies. BB, JLI, JM, JR and MP-V obtained the data. TR-B and TL-J conducted the statistical analysis. All authors contributed to the interpretation of the results. YR-M and MP-V wrote the first draft of the manuscript. All authors read, contributed and approved the final version of the manuscript.

Funding This project has been funded by the Carlos III Health Institute (Ministry of Economy and Competitiveness, Spain) with a grant for research projects on health (PI11/01413) through the Network for Prevention and Health Promotion in Primary Care (redlAPP, RD12/0005/0001; RD16/0007/0001), and by European Union ERDF funds.

Competing interests None declared.

Patient consent for publication Not required.

Ethics approval This study follows the tenets of the Helsinki Declaration and of Good Clinical Research Practice and has been approved by the Ethical and Clinical Research Committee of the IDIAP Jordi Gol. Confidentiality was guaranteed through data encryption and anonymisation in agreement with the data confidentiality Law 15/1999.

Provenance and peer review Not commissioned; externally peer reviewed. Data sharing statement № additional data are available.

Open access This is an open access article distributed in accordance with the Creative Commons Attribution Non Commercial (CC BY-NC 4.0) license, which permits others to distribute, remix, adapt, build upon this work non-commercially, and license their derivative works on different terms, provided the original work is 
properly cited, appropriate credit is given, any changes made indicated, and the use is non-commercial. See: http://creativecommons.org/licenses/by-nc/4.0/.

\section{REFERENCES}

1. Jha P. Avoidable global cancer deaths and total deaths from smoking. Nat Rev Cancer 2009;9:655-64.

2. Murray CJ, Lopez AD. Alternative projections of mortality and disability by cause 1990-2020: Global Burden of Disease Study. Lancet 1997;349:1498-504.

3. World Health Organization, and Tobacco Free Initiative. Building blocks to tobacco control: a hand-book. (Tools for advancing tobacco control in the 21st century). Geneva: WHO, 2004.

4. Federico B, Mackenbach JP, Eikemo TA, et al. Impact of the 2005 smoke-free policy in Italy on prevalence, cessation and intensity of smoking in the overall population and by educational group. Addiction 2012;107:1677-86.

5. Hahn EJ, Rayens MK, Butler KM, et al. Smoke-free laws and adult smoking prevalence. Prev Med 2008;47:206-9.

6. Nagelhout GE, Willemsen MC, de Vries $\mathrm{H}$. The population impact of smoke-free workplace and hospitality industry legislation on smoking behaviour. Findings from a national population survey. Addiction 2011;106:816-23.

7. Hublet A, Schmid H, Clays E, et al. Association between tobacco control policies and smoking behaviour among adolescents in 29 European countries. Addiction 2009;104:1918-26.

8. Tchicaya A, Lorentz N, Demarest S. Socioeconomic inequalities in smoking and smoking cessation due to a smoking ban: general population-based cross-sectional study in Luxembourg. PLoS One 2016;11:e0153966-15.

9. Ye X, Chen S, Yao Z, et al. Smoking behaviors before and after implementation of a smoke-free legislation in Guangzhou, China. BMC Public Health 2015;15:982.

10. Fichtenberg CM, Glantz SA. Effect of smoke-free workplaces on smoking behaviour: systematic review. BMJ 2002;325:188.

11. Frazer K, Callinan JE, McHugh J, et al. Legislative smoking bans for reducing harms from secondhand smoke exposure, smoking prevalence and tobacco consumption. Cochrane Database Syst Rev 2016;2:CD005992.

12. Agencia Estatal Boletín Oficial Del Estado. Ley de medidas sanitarias frente al tabaquismo y reguladora de la venta, el suministro y la publicidad de los productos del tabaco. $2005 \mathrm{https}: / /$ www.boe.es/ buscar/doc.php?id=BOE-A-2005-21261 (Accessed 6 Mar 2018).

13. Nebot M, Fernández E. Evaluación del impacto de la ley de medidas sanitarias frente al tabaquismo. Grupo de Trabajo en Tabaquismo de la Sociedad Española de Epidemiología. 2009 http://www. seepidemiologia.es/documents/dummy/Monografia- Grupo\% 20Trabajo\%20sobre\%20tabaquismo.pdf.

14. Córdoba R, Villalbí JR, Salvador-Llivina T, et al. [Spain's process of passing effective smoking prevention legislation]. Rev Esp Salud Publica 2006;80:631-45.

15. Nebot M, López MJ, Ariza C, et al. Impact of the Spanish smoking law on exposure to secondhand smoke in offices and hospitality venues: before-and-after study. Environ Health Perspect 2009;117:344-7.

16. Agencia Estatal Boletín Oficial Del Estado. Ley de medidas sanitarias frente al tabaquismo y reguladora de la venta, el suministro y la publicidad de los productos del tabaco (30 December 2010), por la que se modifica la Ley $28 / 2005$, de 26 de diciembre, de medidas sanitarias frente al tabaquismo y reguladora de la venta, el suministro, el consumo y la publicidad de los productos del tabaco. Boletín Oficial del Estado (Spanish Official State Bulletin). 2010 https://www.boe.es/buscar/act.php?id=BOE-A-2010-20138 (Accessed 6 Mar 2018).

17. Regidor E, de Mateo S, Ronda E, et al. Heterogeneous trend in smoking prevalence by sex and age group following the implementation of a national smoke-free law. J Epidemiol Community Health 2011;65:702-8.

18. Regidor E, Pascual C, Giráldez-García C, et al. Impact of tobacco prices and smoke-free policy on smoking cessation, by gender and educational group: Spain, 1993-2012. Int J Drug Policy 2015;26:1215-21.

19. Perez-Rios M, Fernandez E, Schiaffino A, et al. Changes in the prevalence of tobacco consumption and the profile of spanish smokers after a comprehensive smoke-free policy. PLoS One 2015;10:1-9.

20. Jiménez Ruiz CA, Riesco Miranda JA, Altet Gómez N, et al. Impact of legislation on passive smoking in Spain. Respiration 2014;87:190-5.

21. Catalina Romero C, Gelpi Médez JA, Cortés Arcas MV, et al. [Changes in tobacco consumption among workers in Spain since the law 28/2005, health measures against smoking]. Rev Esp Salud Publica 2010;84:223-7.

22. Catalina Romero C, Sainz Gutiérrez JC, Quevedo Aguado L, et al. Prevalence of tobacco consumption among working population after the law 42/2010, Spain. Rev Esp Salud Publica 2012;86:177-88.

23. Grupo de Trabajo en Tabaquismo de la Sociedad Española de Epidemiología. Evaluación de las políticas de control del tabaquismo en España (Leyes 28/2005 y 42/2010) Revisión de la evidencia: Sociedad Española de Epidemiología y Ministerio de Sanidad y Política Social, 2017

24. Lidón-Moyano C, Fu M, Ballbè M, et al. Impact of the Spanish smoking laws on tobacco consumption and secondhand smoke exposure: A longitudinal population study. Addict Behav 2017;75:30-5.

25. Bauzà-Amengual ML, Blasco-González M, Sánchez-Vazquez E, et al. [Impact of the Tobacco Law on the workplace: a follow up study of a cohort of workers in Spain 2005-2007]. Aten Primaria 2010;42:309-13

26. Bolíbar B, Pareja C, Astier-Peña MP, et al. Variability in the performance of preventive services and in the degree of control of identified health problems: a primary care study protocol. BMC Public Health 2008;8:281.

27. World Health Organization. The International Statistical Classification of Diseases and Related Health Problems (ICD-10th revision) classification of mental and behavioural disorders: clinical descriptions and diagnostic guidelines. Geneva: World Health Organization, 1992.

28. Okkes IM, Becker HW, Bernstein RM, et al. The March 2002 update of the electronic version of ICPC-2. A step forward to the use of ICD-10 as a nomenclature and a terminology for ICPC-2. Fam Pract 2002;19:543-6.

29. Kim HJ, Fay MP, Feuer EJ, et al. Permutation tests for joinpoint regression with applications to cancer rates. Stat Med 2000;19:335-51.

30. Martín-Sánchez JC, Martinez-Sanchez JM, Bilal U, et al. Sex and Age Specific Projections of Smoking Prevalence in Spain: A Bayesian Approach. Nicotine Tob Res 2018;20:725-30.

31. Ministerio de Sanidad Servicios Sociales e Igualdad. Encuesta Europea de Salud en España: Determinantes de salud [Internet]. 2014 http://www.msssi.gob.es/estadEstudios/estadisticas/ EncuestaEuropea/pdf/MODULO3RELATIVOweb.pdf.

32. Ramos R, Balló $\mathrm{E}$, Marrugat $\mathrm{J}$, et al. Validity for use in research on vascular diseases of the SIDIAP (Information System for the Development of Research in Primary Care): the EMMA study. Rev Esp Cardiol 2012;65:29-37.

33. Wilson LM, Avila Tang E, Chander G, et al. Impact of tobacco control interventions on smoking initiation, cessation, and prevalence: a systematic review. J Environ Public Health 2012;2012:1-36.

34. Guerrero F, Santonja FJ, Villanueva RJ. Analysing the Spanish smoke-free legislation of 2006: a new method to quantify its impact using a dynamic model. Int J Drug Policy $2011 ; 22: 247-51$

35. Pinilla J, Abásolo I. The effect of policies regulating tobacco consumption on smoking initiation and cessation in Spain: is it equal across socioeconomic groups? Tob Induc Dis 2017;15:8.

36. Longo DR, Johnson JC, Kruse RL, et al. A prospective investigation of the impact of smoking bans on tobacco cessation and relapse. Tob Control 2001:10:267-72.

37. Shang $\mathrm{C}$. The effect of smoke-free air law in bars on smoking initiation and relapse among teenagers and young adults. Int $J$ Environ Res Public Health 2015:12:504-20.

38. Buczkowski K, Marcinowicz L, Czachowski S, et al. Motivations toward smoking cessation, reasons for relapse, and modes of quitting: results from a qualitative study among former and current smokers. Patient Prefer Adherence 2014;8:1353-63.

39. Schillo BA, Keller PA, Betzner AE, et al. Minnesota's smokefree policies: impact on cessation program participants. Am J Prev Med 2012;43:S171-8.

40. Navarra. Ley foral $6 / 2003$, de 14 de febrero, de prevención del consumo de tabaco, de protección del aire respirable y de la promoción de la salud en relación al tabaco. http://www.lexnavarra. navarra.es/detalle.asp?r=3323 (Accessed 31 May 2017 2003).

41. Gili M, García Campayo J, Roca M. [Economic crisis and mental health. SESPAS report 2014]. Gac Sanit 2014;28 Suppl 1(Suppl 1):104-8.

42. World Health Organization. WHO report on the global tobacco epidemic, 2009: implementing smoke-free environments. Geneva: World Health Organization, 2009.

43. Buonanno P, Ranzani M. Thank you for not smoking: evidence from the Italian smoking ban. Health Policy 2013;109:192-9. 
44. Camarelles Guillem F, Dalmau González-Gallarza R, Clemente Jiménez $\mathrm{L}$, et al. Documento de consenso para la atención clínica al tabaquismo en España. Medicina Clínica 2013;140:272.e1-272. e12.

45. López-Campos JL, Ruiz-Ramos M, Fernandez E, et al. Recent lung cancer mortality trends in Europe: effect of national smoke-free legislation strengthening. Eur J Cancer Prev 2018;27:296-302.
46. Jan C, Lee M, Roa R, et al. The association of tobacco control policies and the risk of acute myocardial infarction using hospital admissions data. PLoS One 2014;9:e88784.

47. Rando-Matos $\mathrm{Y}$, Pons-Vigués $\mathrm{M}$, Rodriguez-Blanco T, et al. Effect of comprehensive smoke-free legislation on asthma and coronary disease trends in Spanish primary care patients. Eur $J$ Public Health 2018;28:553-9.

48. Córdoba R, Cabezas C, Camarelles F, et al. Recomendaciones sobre el estilo de vida. Atención Primaria 2012;44:16-22. 